\title{
Traumatic combined valve lesions with aneurysm of the sinus of Valsalva causing late onset of heart
} failure

\author{
SUGATO NAWA, KANAME KUROZUMI, SHIGERU TERAMOTO \\ From the Second Department of Surgery, Okayama University Medical School, Okayama, Japan
}

SUMMARY A 23 year old man was operated on because severe incompetence of the aortic, mitral, and tricuspid valve caused congestive heart failure five months after a violent steering wheel injury. The following abnormalities were found at operation: a disrupted right coronary cusp, a torn chorda of the anterior mitral leaflet, a dilated tricuspid annulus, and an intimal tear on the aortic root near the right coronary ostium that had developed into an aneurysm of the sinus of Valsalva.

\section{Case report}

A healthy 23 year old man met with a traffic accident in July 1985. The steering wheel compressed his chest and he lost consciousness for a few minutes. He was admitted to a local orthopaedic hospital with sternal pain. During a two week stay in hospital he had no symptoms of cardiac tamponade, pneumothorax, or haemothorax. Five months after the accident, however, severe congestive heart failure developed. He was referred to another local hospital; when digoxin and diuretic treatment did not improve his symptoms he was referred to our hospital. We do not know whether the heart murmur was audible when he was discharged by the orthopaedic hospital.

\section{CLINICAL FINDINGS}

Diastolic pressure in both arms was low $(26 \mathrm{~mm} \mathrm{Hg})$. On auscultation grade $4 / 6$ systolic and diastolic murmurs of a to and fro type were heard in the aortic region, radiating to both carotid arteries in systole. A grade $3 / 6$ systolic regurgitant murmur was also heard at the apex, radiating to the axilla and spine. A pulsatile liver was palpable $7 \mathrm{~cm}$ below the right costal margin. A chest radiograph showed a cardiothoracic ratio of $0 \cdot 68$. Laboratory studies were normal.

Requests for reprints to Dr Sugato Nawa, The 2nd Department of Surgery, Okayama University Medical School, Shikata-cho 2-5-1, Okayama, Japan 700 .
Cross sectional echocardiography showed pronounced dilatation of the four cardiac chambers, and moderate depression of left ventricular functions (ejection fraction $54 \%$, per cent fibre shortening $29 \%$, and mean circumferential fibre shortening $0.97 \mathrm{circ} / \mathrm{s})$. Echocardiography also demonstrated a severe deformity of three aortic cusps and poor coaptation of the mitral leaflets near to the posteromedial commissure. Pulsed Doppler examination showed severe to moderate regurgitant flow across the tricuspid, mitral, and aortic valves.

Cardiac catheterisation had been carried out at the referring hospital; it had demonstrated moderately raised pressure in the right ventricle $(55 / 4 \mathrm{~mm} \mathrm{Hg})$ and in the main pulmonary artery $(58 / 33 \mathrm{~mm} \mathrm{Hg}$ ). Monoplane left ventricular and aortic root contrast cineangiograms obtained by the referring hospital showed severe (3/4) aortic and mitral regurgitation. The quality of the cineangiograms was very poor. Uneven opacity of the aortic root was seen in the aortogram, but echocardiography and pulsed Doppler examination detected no further abnormality.

On the basis of these data open heart surgery was planned. Further invasive examination was not proposed because there had been cardiac decompensation immediately after cardiac catheterisation.

FINDINGS AND PROCEDURES AT OPERATION The tricuspid annulus was markedly dilated but it had not been damaged. Careful examination of the mitral complex through the atrial septotomy showed a torn chorda and a thickened flailed area on the anterior mitral leaflet near to the posteromedial 
commissure. This lesion caused incompetence of the mitral valve. Moreover, in addition to the considerable deformity of the left and non-coronary cusps of the aortic valve, the right coronary cusp was severely disrupted. This cusp was lacerated at the bottom and only the bilateral commissural portions remained attached to the aorta. There was an intimal tear $(1.0 \mathrm{~cm}$ long) in the right coronary sinus that was floored with old blood clots.

The tear was approximated with buttressed sutures and the severely disrupted aortic valve was replaced by a mechanical prosthetic valve (Omniscience, $25 \mathrm{~mm}$ ). The torn mitral chorda was reimplanted into a neighbouring chorda and mitral annuloplasty was performed on the posteromedial commissure by the unilateral Kay's technique. ${ }^{1}$ The dilated tricuspid annulus was corrected by $\mathrm{De}$ Vega's method. ${ }^{2}$

The patient survived the operation and his postoperative course was uneventful. Cardiac catheterisation after operation showed that the pressure in the right ventricle had fallen to $23 / 2 \mathrm{~mm} \mathrm{Hg}$ and pressure in the main pulmonary artery to $26 / 11 \mathrm{~mm} \mathrm{Hg}$. The area-length method also showed a reduction in end diastolic and end systolic volume indices of 147 and $79 \mathrm{ml} / \mathrm{m}^{2}$ from the preoperative values of 302 and $173 \mathrm{ml} / \mathrm{m}^{2}$ respectively. Postoperative echocardiography showed similar reductions in left heart dimensions and an improved cardiac function. Postoperative cineangiography demonstrated excellent re-establishment of tricuspid, mitral, and aortic valve competences. Unfortunately it was only at this stage that the aneurysm of the right coronary sinus of Valsalva was apparent. It had been overlooked preoperatively.

\section{Discussion}

Important cardiac trauma occurs in $10 \%$ to $20 \%$ of the victims of fatal motor vehicle accidents. ${ }^{3}$ The symptoms of cardiac injuries may be fulminant or delayed, occurring hours, days, and sometimes even years after the injury. ${ }^{4}$ We do not know when incompetence of the aortic and mitral valves developed in the present case. We do not know what the findings at auscultation were when the patient was examined before discharge from the orthopaedic hospital, when the heart size and shape appeared to be normal. The laceration of the right coronary cusp and the intimal tear in the same sinus of Valsalva suggest that aortic valve incompetence was caused by injury. The aortic wall and valve injuries in this case are typical of damage caused by a water hammer phenomenon. We cannot be certain that tearing of the chorda in the mitral apparatus occurred when the aortic valve and sinus of Valsalva were dis $-\frac{?}{c}$ rupted. We think that damage to both the mitral and aortic valves is likely to have been caused by the impact of the steering wheel. A pathophysiologicalo mechanism has been proposed to explain the occur-들 rence of mitral damage, ${ }^{45}$ and Kissane et al have $\frac{\overline{\bar{N}}}{\bar{T}}$ described mitral regurgitation after external chest $\frac{\Phi}{\propto}$ injury in dogs. ${ }^{6}$

We believe that the tricuspid regurgitation was $a_{-}^{\text {के }}$ secondary effect of severe volume overload of the left.. heart; apart from dilatation of the annulus we found $\vec{\omega}$ no signs of injury to the tricuspid valve. Secondary tricuspid incompetence is often associated with more conventional acquired valve disease.

Cardiovascular injuries have been reported after. chest injury 578 ; but these reports do not includecu cases in which operation was needed for traumatic $\forall$ combined valve regurgitation with aortic root음 intimal tear causing aneurysm of the sinus of Val-salva. Cuadros et al reported a similar case in which $>$ there was mitral regurgitation caused by partial laceration of papillary muscle, circumferential $\vec{\bullet}$ laceration of the aortic root, and rupture of the pericardium, ${ }^{4}$ but in their case there was no aortic ${ }^{-}$ regurgitation or sinus aneurysm.

The aneurysm of the sinus of Valsalva was overlooked preoperatively because only a poor qualityo aortic root angiogram in the right anterior oblique $\frac{\mathrm{O}}{\mathrm{D}}$ projection was available from the local hospital. The very faint abnormal silhouette of the aneurysm was $\overrightarrow{\vec{O}}$ masked by the contrast in the aortic root. The lesion 3 was missed on preoperative cross sectional echocardiography because abnormal anteriorly projected? echoes from the aortic root were erroneously interpreted as ghost echoes. The simple approximation of torn intimal edges with buttressed sutures was notsufficient to achieve complete closure of the 3 . aneurysmal lesion, and a postoperative cineangiogram clearly showed the residual aneurysm.

We intend to monitor this residual lesion by serialo cross sectional echocardiographic studies. ${ }^{9}$ A second operation may be inevitable. 910

The resected aortic cusp showed no evidence of inflammation; however, the lacerated right coronaryo cusp showed myxoid degeneration, almost complete 0 absence of elastic fibres, and cystic degeneration $N$ The mitral valve complex was of normal appearances except for the small flailed portion where a fibrous thickening was observed. The change was considered to be secondary to regurgitant flow. The histo $\stackrel{\text { s }}{?}$ logical changes seen in the aortic valve were noto found in the mitral valve. In this patient there mayo have been histopathological degeneration in the aortic valve before the accident that made it more vulnerable to the forces generated by steering whee compression. 
References

1 Kay JH, Zubiate P, Mendez MA, Vanstrom N, Yokoyama T. Mitral valve repair for significant mitral insufficiency. Am Heart J 1978;96:253-62.

2 De Vega NG. La annuloplastia selectiva regulable y permanente. Una técnica originale para et tratamiento de la insuficiencia tricuspide. Rev Esp Cardiol 1972;25:555-6.

3 Barber $\mathrm{H}$. The effects of trauma, direct and indirect, on the heart. $Q J$ Med 1944;13:137-67.

4 Cuadros CL, Hutchinson JE, Mogtader AH. Laceration of a mitral papillary muscle and the aortic root as a result of blunt trauma to the chest. $J$ Thorac Cardiovasc Surg 1984;88:134-40.

5 Parmley LE, Manion WC, Mattingly TW. Nonpenetrating traumatic injury of the heart. Circulation 1958;18:371-96.
6 Kissane RW, Fidler RS, Koons RA. Electrocardiographic changes following external chest injury to dogs. Ann Intern Med 1937;11:907-35.

7 Sklar JS, Clarke D, Campbell D, Pearce B, Apperetti $\mathrm{K}$, Johnson $\mathrm{M}$. Traumatic ventricular septal defect and lacerated mitral leaflet. Chest 1982;81:247-9.

8 Rashid A, Chandrarata PA, Hildner FJ, Samet P, Yahr WZ, Greenberg J. Papillary muscle rupture following nonpenetrating chest trauma. Report of a case with hemodynamic and serial echocardiographic findings and successful surgical treatment. Heart Lung 1978;7:647-51.

9 Miller FA, Seward JB, Gersh BJ, Tajik AJ, Mucha P. Two-dimensional echocardiographic findings in cardiac trauma. Am J Cardiol 1982;50:1022-7.

10 Faillace RT, Greenland P, Nanda NC. Rapid expansion of a saccular aneurysm on the left coronary sinus of Valsalva: a role for early surgical repair? $\mathrm{Br}$ Heart $J$ 1985;54:442-4. 